\title{
Excess Transport Properties of Binary Mixtures of Quinoline with Xylenes at Different Temperatures
}

\author{
Sk. Fakruddin, ${ }^{1}$ Ch. Srinivasu, ${ }^{2}$ B. R. Venkateswara Rao, ${ }^{1}$ and K. Narendra ${ }^{1}$ \\ ${ }^{1}$ Department of Physics, Velagapudi Ramakrishna Siddhartha Engineering College, Andhra Pradesh, Vijayawada 520007, India \\ ${ }^{2}$ Department of Physics, Andhra Loyola College, Vijayawada 520008, India
}

Correspondence should be addressed to K. Narendra, narenk75@gmail.com

Received 23 June 2012; Accepted 3 September 2012

Academic Editor: Leonardo Palmisano

Copyright ( 2012 Sk. Fakruddin et al. This is an open access article distributed under the Creative Commons Attribution License, which permits unrestricted use, distribution, and reproduction in any medium, provided the original work is properly cited.

\begin{abstract}
The ultrasonic velocity and density of binary liquid mixtures of quinoline with o-xylene, m-xylene, and p-xylene have been measured over the entire range of composition at $T=303.15,308.15,313.15$, and $318.15 \mathrm{~K}$. Using these data, various parameters like adiabatic compressibility $(\beta)$, intermolecular free length $\left(L_{f}\right)$, and acoustic impedance $(Z)$ and some excess parameters like excess adiabatic compressibility $\left(\beta^{\mathrm{E}}\right)$, excess intermolecular free length $\left(L_{f}^{E}\right)$, excess acoustic impedance $\left(Z^{E}\right)$, and excess ultrasonic velocity $\left(u^{E}\right)$ have been calculated for all the three mixtures. The calculated deviations and excess functions have been fitted to Redlich-Kister polynomial equation. The observed deviations have been explained on the basis of the intermolecular interactions present in these mixtures.
\end{abstract}

\section{Introduction}

In studying the molecular interactions and physicochemical behaviour of binary liquid mixtures $[1,2]$, the knowledge of thermodynamic and acoustical properties is of great importance. The results are frequently used in process design in many chemical and industrial processes. The studies of binary mixtures containing aromatic hydrocarbons are interesting because they find applications in preferential interactions of polymers in mixed solvents and the studies of polymer phase diagrams. Quinoline is widely used in the manufacturing of dyes, pesticides, and solvent for resins and terpenes. Xylenes are used in printing, rubber, and leather industries. Basically, a binary liquid mixture is formed by the replacement of like contacts in pure liquids by unlike contacts in the mixture. The quantitative and qualitative analyses of excess functions provide information about the nature of molecular interactions in the binary mixtures [3-5]. The literature survey reveals that there has been practically no study of the binary mixtures of these systems from the point of view of their ultrasonic behaviour.

In an attempt to explain the nature of interactions occurring between quinoline and xylenes, ultrasonic velocity and density of binary liquid mixtures of quinoline $+\mathrm{o}-$ xylene/m-xylene/p-xylene have been determined over the entire range of composition at $T=303.15,308.15,313.15$, and $318.15 \mathrm{~K}$. Using the experimental values of $u$ and $\rho$, adiabatic compressibility $(\beta)$, intermolecular free length $\left(L_{f}\right)$, and acoustic impedance $(Z)$ and some excess parameters like excess adiabatic compressibility $\left(\beta^{E}\right)$, excess intermolecular free length $\left(L_{f}{ }^{E}\right)$, excess acoustic impedance $\left(Z^{E}\right)$, and excess ultrasonic velocity $\left(u^{E}\right)$ have been calculated. The results were fitted to the Redlich-Kister polynomial equation. In the light of excess parameters, the intermolecular interactions have been estimated [8].

\section{Experimental}

2.1. Materials. The mass fraction of the liquids (obtained from Merck) is as follows: o-xylene (0.980), m-xylene (0.980), p-xylene (0.990), and quinoline (0.987). All the liquids used were further purified by standard procedure [9]. The purity of the samples was checked by comparing the experimental values of ultrasonic velocity and density with those available in the literature $[6,7]$ and these values are compiled in Table 1. 
TABLE 1: Comparison of experimental values of ultrasonic velocities $(u)$ and densities $(\rho)$ of pure liquids with the values reported in the literature.

\begin{tabular}{|c|c|c|c|c|c|}
\hline \multirow{2}{*}{ Liquid } & \multirow{2}{*}{$T / \mathrm{K}$} & \multicolumn{2}{|c|}{$u /\left(m \cdot s^{-1}\right)$} & \multicolumn{2}{|c|}{$\rho /\left(\mathrm{Kg} \cdot \mathrm{m}^{-3}\right)$} \\
\hline & & Experimental & Literature & Experimental & Literature \\
\hline Quinoline & 303.15 & 1553.68 & $1547^{a}$ & 1085.45 & $1085.79^{a}$ \\
\hline o-xylene & 308.15 & 1338.75 & $1328.30^{\mathrm{b}}$ & 870.70 & $870.73^{b}$ \\
\hline m-xylene & 313.15 & 1304.21 & $1300.34^{\mathrm{b}}$ & 855.70 & $855.47^{b}$ \\
\hline p-xylene & 318.15 & 1288.43 & $1289.68^{\mathrm{b}}$ & 852.80 & $852.26^{\mathrm{b}}$ \\
\hline
\end{tabular}

${ }^{a}$ Nath [6].

${ }^{\mathrm{b}}$ Al-Kandary et al. [7].

TABle 2: Ultrasonic velocities $(u)$ and densities $(\rho)$ for binary mixtures at $T=303.15,308.15,313.15$, and $318.15 \mathrm{~K}$.

\begin{tabular}{|c|c|c|c|c|c|c|c|c|}
\hline \multirow{2}{*}{$x_{1}$} & \multicolumn{2}{|c|}{$T=303.15 \mathrm{~K}$} & \multicolumn{2}{|c|}{$T=308.15 \mathrm{~K}$} & \multicolumn{2}{|c|}{$T=313.15 \mathrm{~K}$} & \multicolumn{2}{|c|}{$T=318.15 \mathrm{~K}$} \\
\hline & $u /\left(\mathrm{m} \cdot \mathrm{s}^{-1}\right)$ & $\rho /\left(\mathrm{Kg} \cdot \mathrm{m}^{-3}\right)$ & $u /\left(\mathrm{m} \cdot \mathrm{s}^{-1}\right)$ & $\rho /\left(\mathrm{Kg} \cdot \mathrm{m}^{-3}\right)$ & $u /\left(\mathrm{m} \cdot \mathrm{s}^{-1}\right)$ & $\rho /\left(\mathrm{Kg} \cdot \mathrm{m}^{-3}\right)$ & $u /\left(\mathrm{m} \cdot \mathrm{s}^{-1}\right)$ & $\rho /\left(\mathrm{Kg} \cdot \mathrm{m}^{-3}\right)$ \\
\hline \multicolumn{9}{|c|}{ Quinoline (1) + o-xylene (2)\} } \\
\hline 0.0000 & 1338.75 & 870.70 & 1315.00 & 869.40 & 1297.50 & 867.70 & 1278.15 & 865.90 \\
\hline 0.1022 & 1384.84 & 901.40 & 1368.21 & 896.79 & 1357.89 & 893.69 & 1348.42 & 891.31 \\
\hline 0.2039 & 1404.42 & 922.99 & 1386.95 & 919.02 & 1376.84 & 915.51 & 1366.21 & 911.50 \\
\hline 0.3051 & 1424.21 & 942.22 & 1408.89 & 936.59 & 1399.42 & 932.06 & 1387.95 & 929.86 \\
\hline 0.4058 & 1444.32 & 961.85 & 1430.84 & 956.70 & 1422.53 & 952.25 & 1411.02 & 948.11 \\
\hline 0.5060 & 1465.26 & 981.69 & 1453.95 & 977.92 & 1445.79 & 974.98 & 1436.16 & 967.28 \\
\hline 0.6058 & 1484.84 & 1001.73 & 1475.37 & 998.64 & 1469.05 & 995.28 & 1460.42 & 990.71 \\
\hline 0.7050 & 1504.47 & 1027.16 & 1496.32 & 1022.00 & 1492.00 & 1018.22 & 1484.05 & 1013.23 \\
\hline 0.8038 & 1523.58 & 1047.92 & 1517.95 & 1042.71 & 1513.47 & 1039.33 & 1506.68 & 1036.86 \\
\hline 0.9021 & 1541.21 & 1067.14 & 1538.42 & 1063.23 & 1534.95 & 1060.07 & 1528.63 & 1057.61 \\
\hline 1.0000 & 1553.68 & 1085.45 & 1550.68 & 1082.11 & 1547.37 & 1078.60 & 1541.05 & 1074.99 \\
\hline \multicolumn{9}{|c|}{ Quinoline (1) + m-xylene (2)\} } \\
\hline 0.0000 & 1304.21 & 855.70 & 1285.27 & 848.70 & 1266.32 & 845.80 & 1244.21 & 840.50 \\
\hline 0.1038 & 1375.05 & 887.18 & 1362.89 & 880.54 & 1354.74 & 875.63 & 1345.26 & 871.03 \\
\hline 0.2067 & 1398.26 & 913.84 & 1384.79 & 910.65 & 1373.68 & 904.25 & 1361.05 & 900.75 \\
\hline 0.3088 & 1420.05 & 931.94 & 1407.74 & 925.52 & 1395.26 & 921.60 & 1382.63 & 918.29 \\
\hline 0.4100 & 1440.16 & 952.56 & 1428.68 & 945.83 & 1418.37 & 942.91 & 1406.89 & 940.30 \\
\hline 0.5104 & 1461.95 & 978.74 & 1452.63 & 974.27 & 1443.47 & 969.91 & 1432.84 & 966.98 \\
\hline 0.6099 & 1482.53 & 998.14 & 1474.35 & 996.30 & 1466.89 & 992.34 & 1457.26 & 989.29 \\
\hline 0.7086 & 1502.32 & 1014.85 & 1495.16 & 1011.43 & 1488.84 & 1009.59 & 1479.89 & 1006.23 \\
\hline 0.8066 & 1521.42 & 1043.74 & 1516.79 & 1038.14 & 1511.32 & 1034.56 & 1503.21 & 1031.79 \\
\hline 0.9037 & 1532.89 & 1066.84 & 1529.26 & 1062.01 & 1525.79 & 1059.32 & 1519.47 & 1056.74 \\
\hline 1.0000 & 1553.68 & 1085.45 & 1550.68 & 1082.11 & 1547.37 & 1078.60 & 1541.05 & 1074.99 \\
\hline \multicolumn{9}{|c|}{ Quinoline $(1)+$ p-xylene $(2)$} \\
\hline 0.0000 & 1288.43 & 852.80 & 1275.79 & 846.00 & 1253.68 & 843.00 & 1234.73 & 836.90 \\
\hline 0.1041 & 1371.89 & 885.76 & 1361.74 & 878.51 & 1351.57 & 874.51 & 1342.10 & 869.20 \\
\hline 0.2073 & 1395.10 & 909.41 & 1384.63 & 903.39 & 1375.52 & 901.61 & 1360.89 & 898.74 \\
\hline 0.3095 & 1415.89 & 929.81 & 1406.57 & 918.62 & 1402.10 & 917.24 & 1389.47 & 915.55 \\
\hline 0.4108 & 1436.00 & 949.85 & 1428.02 & 942.34 & 1424.21 & 938.40 & 1412.73 & 938.07 \\
\hline 0.5112 & 1457.79 & 976.74 & 1451.47 & 971.93 & 1446.31 & 969.00 & 1434.68 & 965.25 \\
\hline 0.6107 & 1480.37 & 997.73 & 1473.89 & 995.26 & 1472.73 & 991.22 & 1463.10 & 988.58 \\
\hline 0.7093 & 1500.15 & 1013.63 & 1494.50 & 1010.43 & 1493.68 & 1009.37 & 1484.73 & 1005.40 \\
\hline 0.8071 & 1518.26 & 1043.03 & 1514.63 & 1037.13 & 1509.16 & 1033.54 & 1501.05 & 1030.18 \\
\hline 0.9040 & 1530.73 & 1066.53 & 1527.10 & 1061.60 & 1522.63 & 1058.00 & 1515.31 & 1056.23 \\
\hline 1.0000 & 1553.68 & 1085.45 & 1550.68 & 1082.11 & 1547.37 & 1078.60 & 1541.05 & 1074.99 \\
\hline
\end{tabular}


TABle 3: Coefficients of Redlich-Kister equation $\left(A_{i}\right)$ and standard deviations $(\sigma)$ for excess adiabatic compressibility $\left(\beta^{E}\right)$, excess intermolecular free length $\left(L_{f}{ }^{E}\right)$, excess acoustic impedance $\left(Z^{E}\right)$, and excess ultrasonic velocity $\left(u^{E}\right)$ for binary liquid mixtures.

\begin{tabular}{|c|c|c|c|c|c|}
\hline Properties & $T / \mathrm{K}$ & $A_{0}$ & $A_{1}$ & $A_{2}$ & $\sigma$ \\
\hline \multicolumn{6}{|c|}{ Quinoline $(1)+$ o-xylene $(2)$} \\
\hline \multirow{4}{*}{$10^{-11} \beta^{E} /\left(\mathrm{m}^{2} \cdot \mathrm{N}^{-1}\right)$} & 303.15 & -14.2750 & 15.7470 & -19.3987 & 0.6231 \\
\hline & 308.15 & -28.7822 & 50.6552 & -42.1525 & 2.1127 \\
\hline & 313.15 & -17.6239 & 21.2062 & -27.0003 & 0.9585 \\
\hline & 318.15 & -18.7916 & 26.9112 & -35.7657 & 1.2192 \\
\hline \multirow{4}{*}{$10^{-4} L_{f}^{E} /(\mathrm{m})$} & 303.15 & -15.4753 & 18.3256 & -25.1069 & 0.7669 \\
\hline & 308.15 & -17.0736 & 20.3448 & -29.2354 & 0.9519 \\
\hline & 313.15 & -18.8797 & 24.2345 & -34.6635 & 1.1721 \\
\hline & 318.15 & -19.8516 & 30.8846 & -45.9429 & 1.4765 \\
\hline \multirow{4}{*}{$10^{4} Z^{E} /\left(\mathrm{Kg} \cdot \mathrm{m}^{2} \cdot \mathrm{s}^{-1}\right)$} & 303.15 & 3.8618 & -13.7678 & 27.2629 & 0.6353 \\
\hline & 308.15 & 3.3493 & -12.9783 & 28.4726 & 0.7100 \\
\hline & 313.15 & 3.7404 & -14.2036 & 31.6728 & 0.8641 \\
\hline & 318.15 & 1.8696 & -17.0587 & 42.6292 & 0.9230 \\
\hline \multirow{4}{*}{$u^{E} /\left(\mathrm{m} \cdot \mathrm{s}^{-1}\right)$} & 303.15 & 72.2489 & -105.2525 & 169.0334 & 5.2762 \\
\hline & 308.15 & 80.2265 & -123.8911 & 219.0926 & 6.9440 \\
\hline & 313.15 & 89.2298 & -154.6148 & 264.9103 & 8.2814 \\
\hline & 318.15 & 102.3393 & -204.3521 & 328.8972 & 11.0408 \\
\hline \multicolumn{6}{|c|}{ Quinoline $(1)+$ m-xylene $(2)$} \\
\hline \multirow{4}{*}{$10^{-11} \beta^{E} /\left(\mathrm{m}^{2} \cdot \mathrm{N}^{-1}\right)$} & 303.15 & -21.9058 & 31.4522 & -26.7769 & 1.1162 \\
\hline & 308.15 & -24.3389 & 36.3768 & -31.2803 & 1.3641 \\
\hline & 313.15 & -26.3980 & 42.3813 & -39.2213 & 1.7172 \\
\hline & 318.15 & -30.0673 & 51.5898 & -49.7464 & 2.1494 \\
\hline \multirow{4}{*}{$10^{-4} L_{f}^{E} /(\mathrm{m})$} & 303.15 & -24.3607 & 37.6519 & -32.0435 & 1.3789 \\
\hline & 308.15 & -26.8359 & 43.2278 & -37.1303 & 1.6805 \\
\hline & 313.15 & -28.8479 & 49.9906 & -46.9235 & 2.0995 \\
\hline & 318.15 & -32.7902 & 60.3208 & -59.4502 & 2.5997 \\
\hline \multirow{4}{*}{$10^{4} Z^{E} /\left(\mathrm{Kg} \cdot \mathrm{m}^{2} \cdot \mathrm{s}^{-1}\right)$} & 303.15 & 10.0579 & -27.656 & 25.6108 & 1.0966 \\
\hline & 308.15 & 10.5394 & -30.9755 & 26.8524 & 1.3238 \\
\hline & 313.15 & 10.1966 & -32.6801 & 33.4784 & 1.4769 \\
\hline & 318.15 & 11.9598 & -37.0021 & 41.4323 & 1.6993 \\
\hline \multirow{4}{*}{$u^{E} /\left(\mathrm{m} \cdot \mathrm{s}^{-1}\right)$} & 303.15 & 127.5056 & -281.9268 & 210.6969 & 11.5612 \\
\hline & 308.15 & 134.0042 & -310.4828 & 252.1364 & 13.3956 \\
\hline & 313.15 & 142.3595 & -363.6245 & 328.7575 & 16.7309 \\
\hline & 318.15 & 157.3428 & -427.7324 & 412.1425 & 20.2179 \\
\hline \multicolumn{6}{|c|}{ Quinoline $(1)+$ p-xylene $(2)$} \\
\hline \multirow{4}{*}{$10^{-11} \beta^{E} /\left(\mathrm{m}^{2} \cdot \mathrm{N}^{-1}\right)$} & 303.15 & -24.3371 & 40.1603 & -34.8069 & 1.4993 \\
\hline & 308.15 & -26.1737 & 42.5118 & -35.8559 & 1.7109 \\
\hline & 313.15 & -30.5317 & 50.6633 & -42.1002 & 1.9289 \\
\hline & 318.15 & -33.3037 & 58.4176 & -51.3519 & 2.2552 \\
\hline \multirow{4}{*}{$10^{-4} L_{f}^{E} /(\mathrm{m})$} & 303.15 & -26.8705 & 48.104 & -41.4238 & 1.8424 \\
\hline & 308.15 & -28.7822 & 50.6552 & -42.1525 & 2.1127 \\
\hline & 313.15 & -33.8045 & 59.9962 & -48.8655 & 2.3611 \\
\hline & 318.15 & -36.5393 & 68.562 & -59.8297 & 2.7239 \\
\hline
\end{tabular}


TABle 3: Continued.

\begin{tabular}{|c|c|c|c|c|c|}
\hline Properties & $T / \mathrm{K}$ & $A_{0}$ & $A_{1}$ & $A_{2}$ & $\sigma$ \\
\hline \multirow{4}{*}{$10^{4} Z^{E} /\left(\mathrm{Kg} \cdot \mathrm{m}^{2} \cdot \mathrm{s}^{-1}\right)$} & 303.15 & 10.6611 & -35.6773 & 32.3543 & 1.4669 \\
\hline & 308.15 & 10.9532 & -36.633 & 29.7221 & 1.7861 \\
\hline & 313.15 & 13.5849 & -41.1183 & 31.3799 & 1.8255 \\
\hline & 318.15 & 14.1107 & -43.7213 & 39.128 & 1.8140 \\
\hline \multirow{4}{*}{$u^{E} /\left(\mathrm{m} \cdot \mathrm{s}^{-1}\right)$} & 303.15 & 143.0469 & -360.5048 & 271.5399 & 14.6146 \\
\hline & 308.15 & 148.7841 & -368.4327 & 277.8589 & 15.3763 \\
\hline & 313.15 & 179.5480 & -431.3940 & 319.9555 & 17.7116 \\
\hline & 318.15 & 184.2120 & -485.6012 & 383.7827 & 21.1574 \\
\hline
\end{tabular}

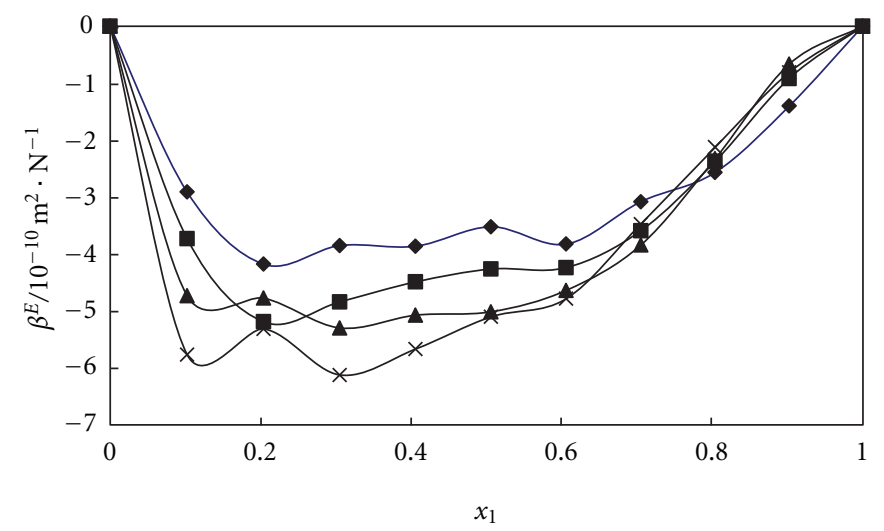

(a)

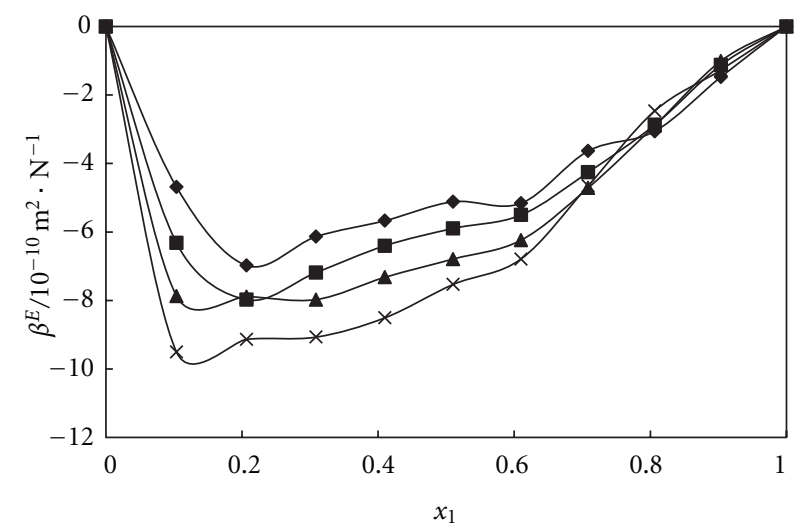

(b)

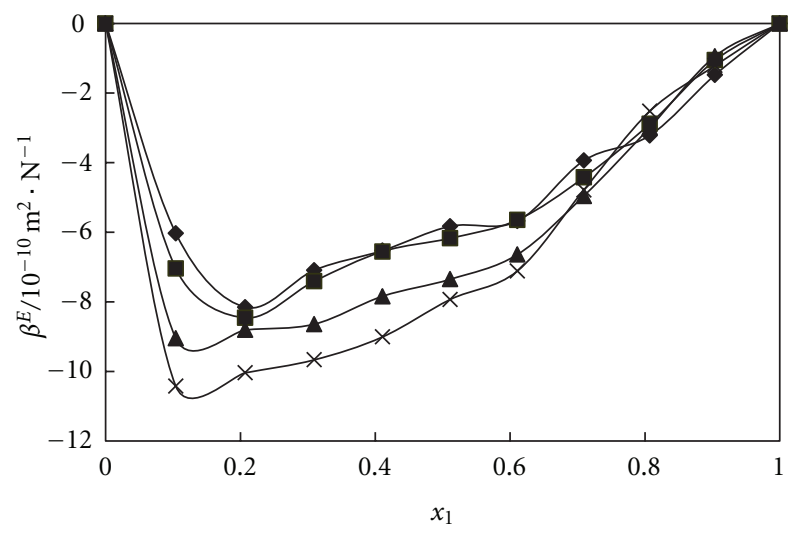

(c)

Figure 1: (a) Plot of excess adiabatic compressibility $\left(\beta^{E}\right)$ versus mole fraction $\left(x_{1}\right)$ for binary liquid mixtures of quinoline with o-xylene at temperatures: $\diamond, 303.15 \mathrm{~K} ; \square, 308.15 \mathrm{~K} ; \boldsymbol{\Delta}, 313.15 \mathrm{~K} ; \times, 318.15 \mathrm{~K}$. (b) Plot of excess adiabatic compressibility $\left(\beta^{E}\right)$ versus mole fraction $\left(x_{1}\right)$ for binary liquid mixtures of quinoline with m-xylene at temperatures: $\downarrow$, $303.15 \mathrm{~K} ; \square, 308.15 \mathrm{~K}$; $\boldsymbol{\Delta}, 313.15 \mathrm{~K}$; $\times$, $318.15 \mathrm{~K}$. (c) Plot of excess compressibility $\left(\beta^{E}\right)$ versus mole fraction $\left(x_{1}\right)$ for binary liquid mixtures of quinoline with p-xylene at temperatures: $\$$, $303.15 \mathrm{~K}$; $\square$, $308.15 \mathrm{~K} ; \boldsymbol{\Delta}, 313.15 \mathrm{~K} ; \times, 318.15 \mathrm{~K}$.

2.2. Procedure. Job's method of continuous variation was used to prepare the mixtures of required proportions. The prepared mixtures were preserved in well-stoppard conical flasks. After mixing the liquids thoroughly, the flasks were left undisturbed to allow them to attain thermal equilibrium.

The ultrasonic velocities were measured by using single crystal ultrasonic pulse echo interferometer (Mittal enterprises, India; Model: F-80X). It consists of a highfrequency generator and a measuring cell. The measurements of ultrasonic velocities were made at a fixed frequency of $3 \mathrm{MHz}$. The capacity of the measuring cell is $12 \mathrm{~mL}$. The calibration of the equipment was done by measuring the velocity in carbon tetrachloride and benzene. The results are in good agreement with those reported in the literature [10]. The ultrasonic velocity has an accuracy of $\pm 0.5 \mathrm{~ms}^{-1}$. The temperature was controlled by circulating water around the liquid cell from thermostatically controlled constant temperature water bath (accuracy $\pm 0.01 \mathrm{~K})$. 


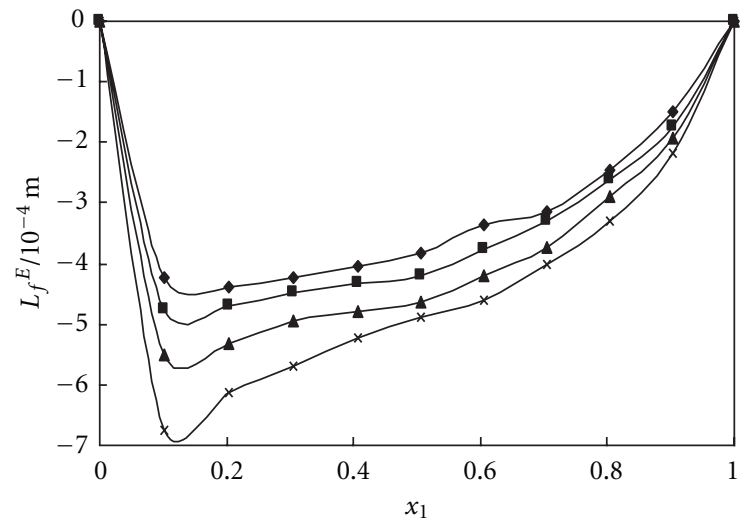

(a)

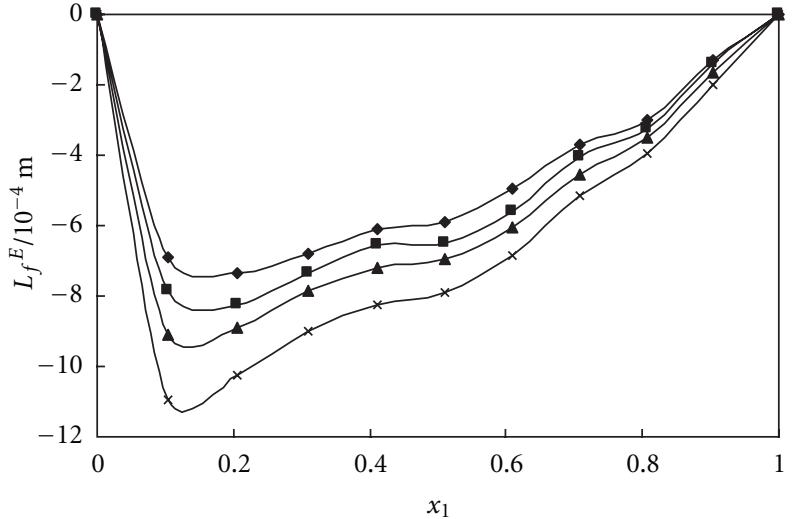

(b)

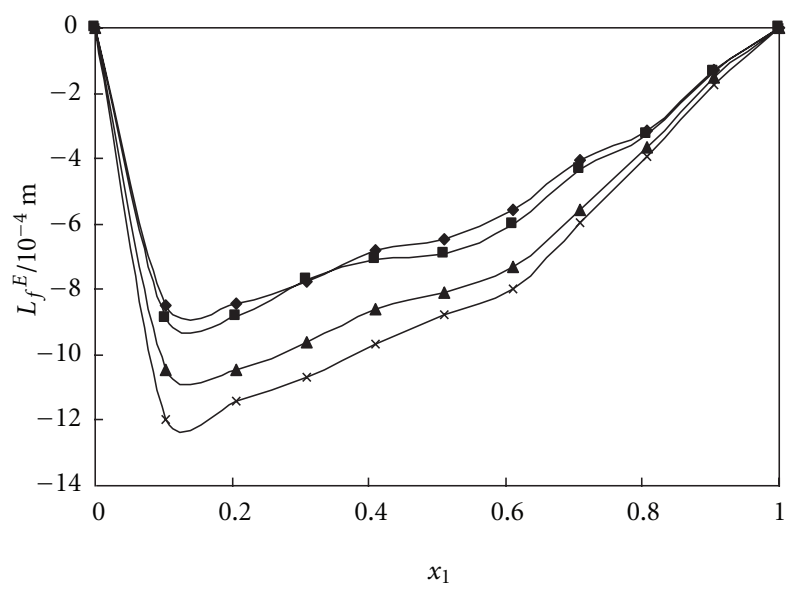

(c)

Figure 2: (a) Plot of excess free length $\left(L_{f}{ }^{E}\right)$ versus mole fraction $\left(x_{1}\right)$ for binary liquid mixtures of quinoline with o-xylene at temperatures: $\checkmark, 303.15 \mathrm{~K} ; \square, 308.15 \mathrm{~K} ; \boldsymbol{\Delta}, 313.15 \mathrm{~K} ; \times, 318.15 \mathrm{~K}$. (b) Plot of excess free length $\left(L_{f}{ }^{E}\right)$ versus mole fraction $\left(x_{1}\right)$ for binary liquid mixtures of quinoline with m-xylene at temperatures: $\diamond, 303.15 \mathrm{~K} ; \square, 308.15 \mathrm{~K} ; \boldsymbol{\Delta}, 313.15 \mathrm{~K} ; \times, 318.15 \mathrm{~K}$. (c) Plot of excess free length $\left(L_{f}{ }^{E}\right)$ versus mole fraction $\left(x_{1}\right)$ for binary liquid mixtures of quinoline with p-xylene at temperatures: $\diamond, 303.15 \mathrm{~K} ; \square, 308.15 \mathrm{~K} ; \mathbf{\Lambda}, 313.15 \mathrm{~K} ; \times, 318.15 \mathrm{~K}$.

The densities of pure liquids and liquid mixtures were measured by using a specific gravity bottle with an accuracy of $\pm 0.5 \%$. An electronic balance (Shimadzu AUY220, Japan), with a precision of $\pm 0.1 \mathrm{mg}$, was used for the mass measurements. Averages of 4-5 measurements were taken for each sample.

\section{Theory}

From the experimental data of ultrasonic velocity and density various thermodynamic parameters are evaluated using standard equations.

Adiabatic compressibility:

$$
\beta=\frac{1}{\rho u^{2}}
$$

where $\rho$ and $u$ are density and ultrasonic velocity, respectively.
Inter molecular free length:

$$
L_{f}=K_{T} \cdot \beta^{1 / 2},
$$

where $K_{T}$ is the temperature dependent constant [11].

Acoustic impedance:

$$
Z=\rho u \text {. }
$$

The strength of interaction between the component molecules of binary mixtures is well reflected in the deviation of the excess functions from ideality [12]. The excess properties such as $\beta^{E}, L_{f}^{E}, Z^{E}$, and $u^{E}$ have been calculated using

$$
Y^{E}=Y_{\text {mix }}-\left[x_{1} Y_{1}+x_{2} Y_{2}\right]
$$

where $Y^{E}$ is $\beta^{E}, L_{f}^{E}, Z^{E}$, or $u^{E}$ and $x$ represents mole fraction of the component and subscript 1 and 2 for the components 1 and 2 , respectively. 


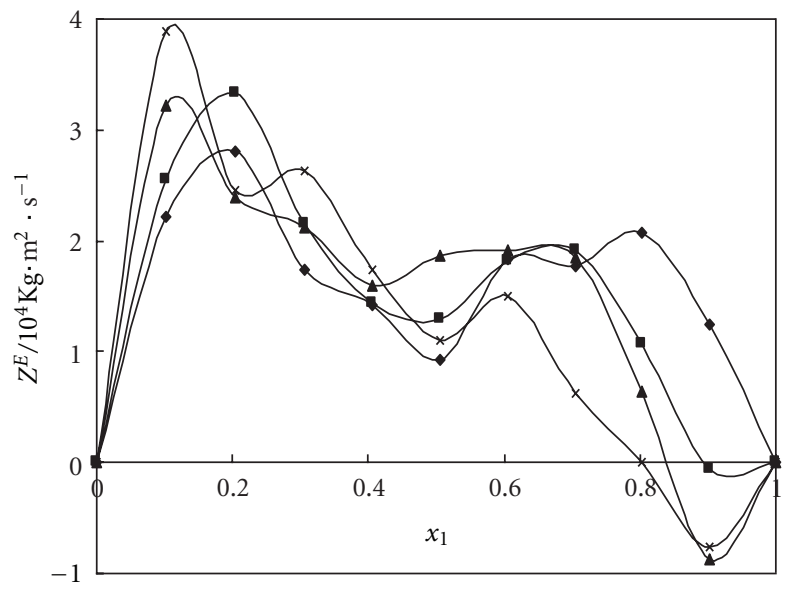

(a)

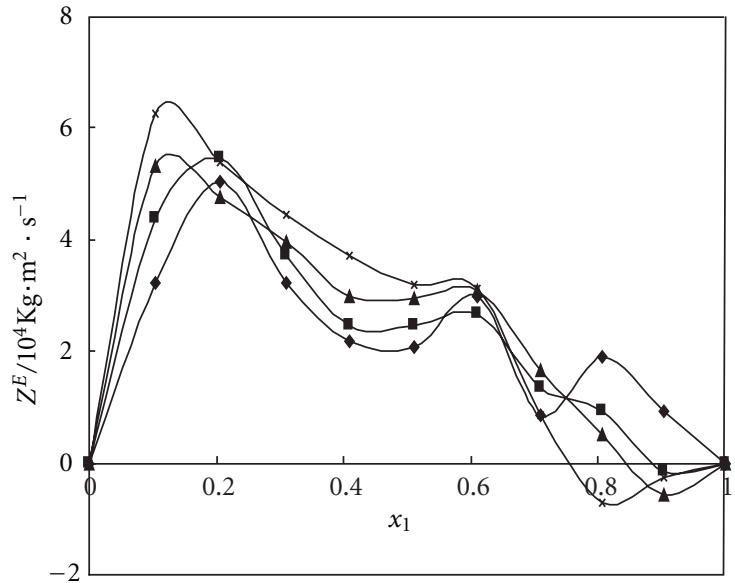

(b)

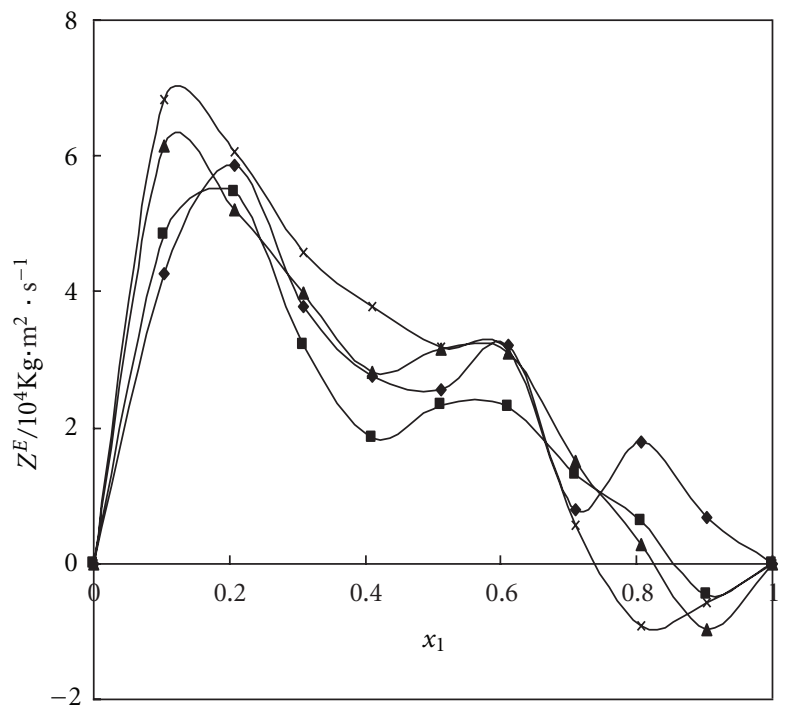

(c)

Figure 3: (a) Plot of excess acoustic impedance $\left(Z^{E}\right)$ versus mole fraction $\left(x_{1}\right)$ for binary liquid mixtures of quinoline with o-xylene at temperatures: $\downarrow, 303.15 \mathrm{~K} ; \square, 308.15 \mathrm{~K} ; \mathbf{\Delta}, 313.15 \mathrm{~K} ; \times, 318.15 \mathrm{~K}$. (b) Plot of excess acoustic impedance $\left(Z^{E}\right)$ versus mole fraction $\left(x_{1}\right)$ for binary liquid mixtures of quinoline with m-xylene at temperatures: $\downarrow$, $303.15 \mathrm{~K} ; \square, 308.15 \mathrm{~K} ; \boldsymbol{\Delta}, 313.15 \mathrm{~K}$; $\times$, $318.15 \mathrm{~K}$. (c) Plot of excess acoustic impedance $\left(Z^{E}\right)$ versus mole fraction $\left(x_{1}\right)$ for binary liquid mixtures of quinoline with p-xylene at temperatures: $\downarrow$, $303.15 \mathrm{~K}$; $\square$, $308.15 \mathrm{~K} ; \mathbf{\Delta}, 313.15 \mathrm{~K} ; \times, 318.15 \mathrm{~K}$.

The excess values of above parameters for each mixture have been fitted to Redlich-Kister polynomial equation [13]:

$$
Y^{E}=X_{1} \cdot X_{2} \sum_{i=0}^{n} A_{i}\left(X_{1}-X_{2}\right)^{i} .
$$

The values of the coefficients $A_{i}$ were calculated by a method of least squares along with the standard deviation $\sigma\left(Y^{E}\right)$. The coefficient is adjustable to the parameters for a better fit of the excess functions. The standard deviation values were obtained from

$$
\sigma\left(Y^{E}\right)=\left[\frac{\sum_{i=1}^{n}\left(Y_{\text {expt }}^{E}-Y_{\text {cal }}^{E}\right)^{2}}{m-n}\right]^{1 / 2}
$$

where $m$ is the number of experimental points, $n$ is the number of parameters, and $Y_{\text {expt }}$ and $Y_{\text {cal }}$ are the experimental and calculated parameters, respectively. 


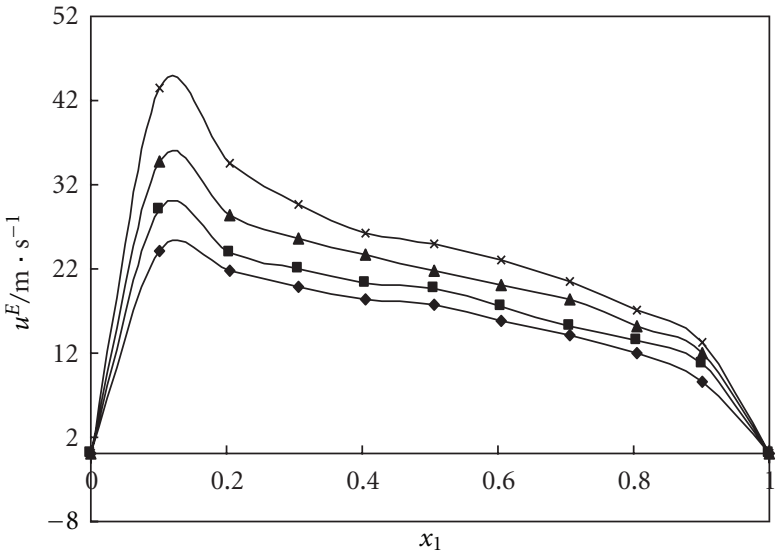

(a)

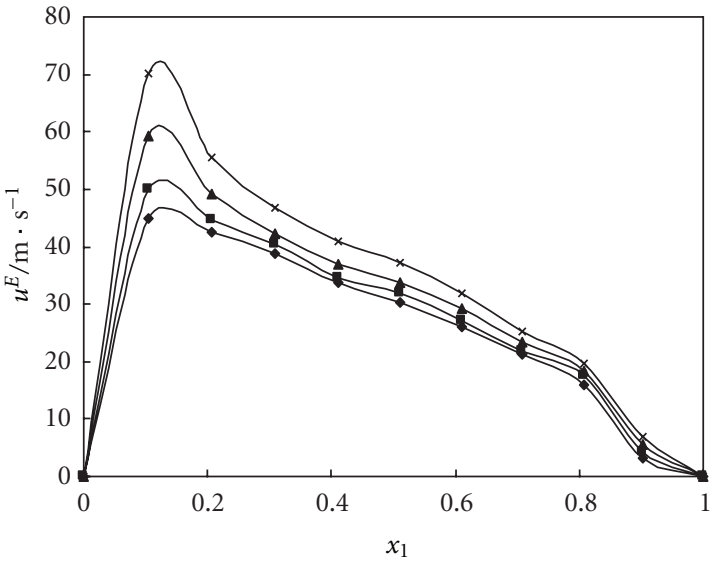

(b)

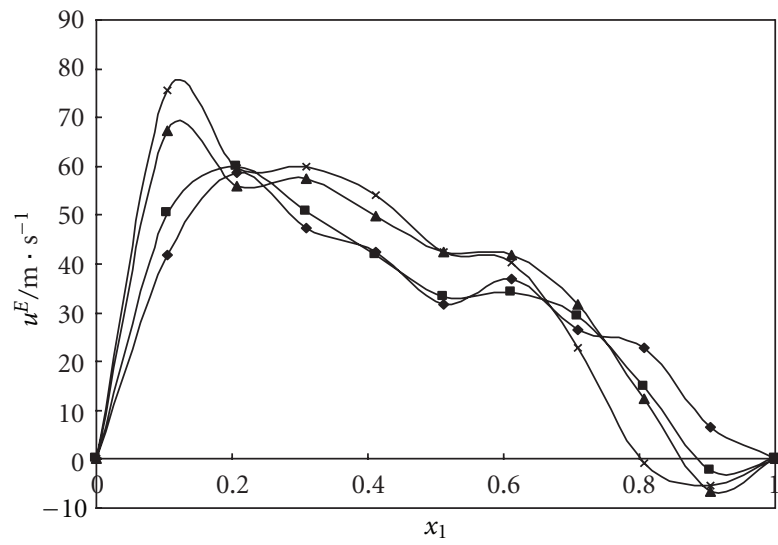

(c)

Figure 4: (a) Plot of excess ultrasonic velocity $\left(u^{E}\right)$ versus mole fraction $\left(x_{1}\right)$ for binary liquid mixtures of quinoline with o-xylene at temperatures: $\$ 303.15 \mathrm{~K} ; \square, 308.15 \mathrm{~K} ; \mathbf{\Lambda}, 313.15 \mathrm{~K} ; \times, 318.15 \mathrm{~K}$. (b) Plot of excess ultrasonic velocity $\left(u^{E}\right)$ versus mole fraction $\left(x_{1}\right)$ for binary liquid mixtures of quinoline with m-xylene at temperatures: $\downarrow, 303.15 \mathrm{~K} ; \square, 308.15 \mathrm{~K} ; \boldsymbol{\Lambda}, 313.15 \mathrm{~K}$; $\times, 318.15 \mathrm{~K}$. (c) Plot of excess ultrasonic velocity $\left(u^{E}\right)$ versus mole fraction $\left(x_{1}\right)$ for binary liquid mixtures of quinoline with p-xylene at temperatures: $\downarrow$, $303.15 \mathrm{~K}$; $\square$, $308.15 \mathrm{~K} ; \boldsymbol{\Delta}, 313.15 \mathrm{~K} ; \times, 318.15 \mathrm{~K}$.<smiles>Cc1cccc(C)c1</smiles>

o-Xylene<smiles>Cc1cccc(C)c1</smiles>

m-Xylene

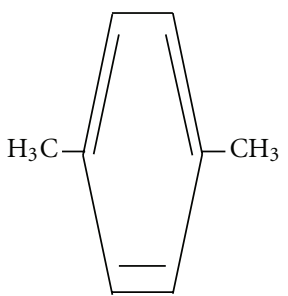

p-Xylene

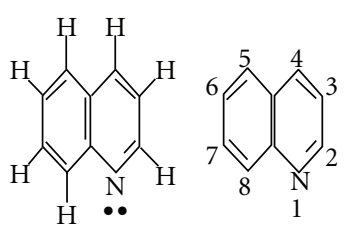

Quinoline

Scheme 1

\section{Results and Discussion}

The structures of the components taken up for study are given in Scheme 1.

The experimental values of ultrasonic velocity $(u)$ and density $(\rho)$ for the three binary mixtures over the entire composition range and at temperatures $T=303.15,308.15$,
313.15 , and $318.15 \mathrm{~K}$ are given in Table 2 . The values of the Redlich-Kister polynomial coefficients $A_{i}$ evaluated by the method of least squares along with standard deviation are given in Table 3. Plots of $\beta^{E}, L_{f}{ }^{E}, Z^{E}$, and $u^{E}$ against mole fraction of quinoline for all the three mixtures are given in Figures 1-4. 
The excess transport properties of the mixtures are influenced by three main types of contributions, namely, (i) due to non specific Van der Waals type forces, (ii) due to hydrogen bonding, dipole-dipole, and donor-acceptor interaction between unlike molecules, and (iii) due to the fitting of smaller molecules into the voids created by the bigger molecules. The first effect leads to contraction in volume hence leads to negative contribution towards $u^{E}$ and positive contribution towards $\beta^{E}$. However, the second effect leads to negative contribution towards $\beta^{E}$ and positive contribution towards $u^{E}$.

For all the three mixtures, the results of the excess adiabatic compressibility $\beta^{E}$ plotted in Figures $1(\mathrm{a})-1(\mathrm{c})$ are negative at all the temperatures studied. The negative values of $\beta^{E}$ suggest that the mixtures are less compressible than the corresponding ideal mixture. According to Fort and Moore [14], the liquids of different molecular size usually mix with decrease in volume yielding negative $\beta^{E}$ values. The strength of the interactions between component molecules increases when excess values tend to become increasingly negative. As the temperature increases, the $\beta^{E}$ values also increase in all the three systems, suggesting that the thermal energy activates the molecules towards complex formation between unlike molecules [15]. It is also observed that the molecular interactions are stronger in quinoline $+\mathrm{o}$-xylene mixture.

From Figures 2(a)-2(c) it is observed that $L_{f}{ }^{E}$ values are negative for the entire mole fraction range, for all the four temperatures in case of all the three mixtures. The $L_{f}{ }^{E}$ values are increasingly negative as the strength of interaction between component molecules increases [16].

The excess values of $Z^{E}$ which are plotted in Figures 3(a)$3(\mathrm{c})$ are all positive in all the three liquid systems over the entire composition range and for all the four temperatures studied. The positive excess values of $Z^{E}$ clearly suggest that there exist strong molecular interactions between the molecules of all the three mixtures [17].

The results for the excess ultrasonic velocity $u^{E}$ plotted in Figures 4(a)-4(c) are positive for all the three mixtures at all the temperatures studied. The positive values of $u^{E}$ increase with the increase in temperature which indicates the increase in strength of interaction with temperature in all the three mixtures. The higher positive values of $u^{E}$ are observed in case of quinoline $+\mathrm{o}$-xylene mixture, because the $-\mathrm{OH}$ group attached to the benzene ring in case of o-xylene is stabilized to a great extent through resonance as compared to other mixtures [18].

\section{Conclusions}

From the data of ultrasonic velocity and density, some thermoacoustical parameters and their excess parameters for the three binary liquid mixtures of quinoline with o-xylene, $\mathrm{m}$-xylene, and p-xylene at $T=303.15,308.15,313.15$, and $318.15 \mathrm{~K}$ are calculated for the entire composition range. From the results of these excess parameters, it is observed that there exists a strong molecular interaction between the unlike molecules in all the three mixtures. The interaction is stronger in case of quinoline $+\mathrm{o}$-xylene mixture as compared to quinoline $+\mathrm{m}$-xylene/p-xylene mixtures. These data will be useful in pharma and perfume industries for handling and mixing processes.

\section{References}

[1] K. Narendra, Ch. Srinivasu, Sk. Fakruddin, and P. N. Murthy, "Excess parameters of binary mixtures of anisaldehyde with ocresol, m-cresol and p-cresol at $T=(303.15,308.15,313.15$, and 318.15) K," The Journal of Chemical Thermodynamics, vol. 43, no. 11, pp. 1604-1611, 2011.

[2] A. Ali, A. Yasmin, and A. K. Nain, "Study of intermolecular interactions in binary liquid mixtures through ultrasonic speed measurement," Indian Journal of Pure and Applied Physics, vol. 40, no. 5, pp. 315-322, 2002.

[3] S. I. Oswal and N. B. Patel, "Speed of sound, isentropic compressibility, viscosity, and excess volume of binary mixtures. 2. Alkanenitriles + dimethylformamide, + dimethylacetamide, and + dimethyl sulfoxide," Journal of Chemical and Engineering Data, vol. 40, no. 4, pp. 845-849, 1995.

[4] R. Mehra and R. Israni, "Effect of temperature on excess molar volumes of binary mixtures of hexadecane and butanol," Indian Journal of Pure and Applied Physics, vol. 38, no. 2, pp. 81-83, 2000.

[5] A. Ali and A. K. Nain, "Study of intermolecular interaction in binary mixtures of formamide with 2-propanol, 1,2propanediol and 1,2,3-propanetriol through ultrasonic speed measurements," Indian Journal of Pure and Applied Physics, vol. 39, pp. 421-427, 2001.

[6] J. Nath, "Ultrasonic velocities, relative permittivities and refractive indices for binary liquid mixtures of trichloroethene with pyridine and quinoline," Fluid Phase Equilibria, vol. 109, no. 1, pp. 39-51, 1995.

[7] J. A. Al-Kandary, A. S. Al-Jimaz, and A. H. M. Abdul-Latif, "Viscosities, densities, and speeds of sound of binary mixtures of benzene, toluene, o-xylene, $\mathrm{m}$-xylene, $\mathrm{p}$-xylene, and mesitylene with anisole at $(288.15,293.15,298.15$, and 303.15) K," Journal of Chemical and Engineering Data, vol. 51, no. 6, pp. 2074-2082, 2006.

[8] S. Parveen, S. Singh, D. Shukla, K. P. Singh, M. Gupta, and J. P. Shukla, "Molecular interaction study of binary mixtures of THF with methanol and o-cresol—an optical and ultrasonic study," Acta Physica Polonica A, vol. 116, no. 6, pp. 1011-1017, 2009.

[9] D. D. Perrin and W. L. F. Armarego, Purification of Laboratory Chemicals, Pergamon Press, Oxford, UK, 3rd edition, 1980.

[10] D. Das and D. K. Hazra, "Molecular interaction study in binary mixtures of $\mathrm{N}, \mathrm{N}$-dimethyl acetamide with 2ethoxyethanol at different temperatures," Indian Journal of Physics B, vol. 77, pp. 519-523, 2003.

[11] B. Jacobson, "Ultrasonic velocity in liquids and liquid mixtures," Journal of Chemical Physics, vol. 6, no. 5, pp. 927-928, 1952.

[12] D. R. Lide, Ed., CRC Handbook of Chemistry and Physics, CRC Press, Boca Raton, Fla, USA, 76th edition, 1995.

[13] O. Redlich and A. T. Kister, "Algebraic representation of thermodynamic properties and the classification of solutions," Indian and Engineering Chemistry, vol. 40, no. 2, pp. 345-348, 1948.

[14] R. J. Fort and W. R. Moore, "Adiabatic compressibilities of binary liquid mixtures," Transactions of the Faraday Society, vol. 61, pp. 2102-2111, 1965. 
[15] S. N. Gour, J. S. Tomar, and R. P. Varma, "Study of molecular interactions in binary mixtures using excess thermodynamic parameters," Indian Journal of Pure and Applied Physics, vol. 24, p. 602, 1986.

[16] A. Ali and A. K. Nain, "Ultrasonic and volumetric study of binary mixtures of benzyl alcohol with amides," Bulletin of the Chemical Society of Japan, vol. 75, pp. 681-687, 2002.

[17] S. Thirumaran and D. George, "Ultrasonic study of intermolecular association through hydrogen bonding in ternary liquid mixtures," Journal of Engineering and Applied Sciences, vol. 4, no. 4, pp. 1-11, 2009.

[18] K. Tiwari, C. Patra, and V. Chakravortty, "Molecular interactions study on binary liquid mixtures of dimethylsulphoxide with benzene, carbontetrachloride and toluene from the excess properties of ultrasonic velocity, density and viscosity," Acoustics Letters, vol. 19, pp. 53-59, 1995. 


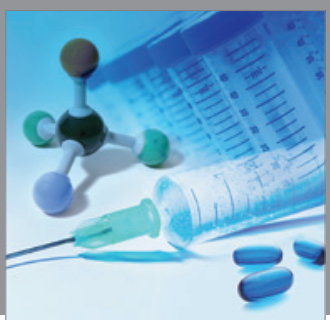

International Journal of

Medicinal Chemistry

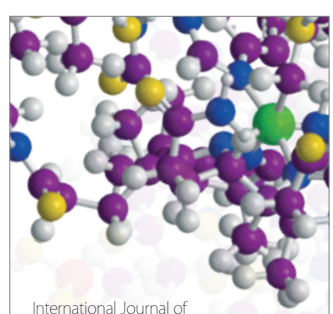

Carbohydrate Chemistry

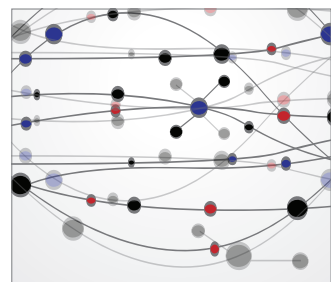

The Scientific World Journal
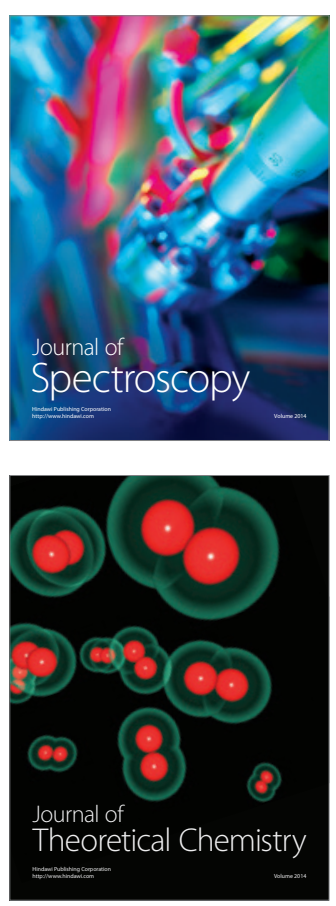
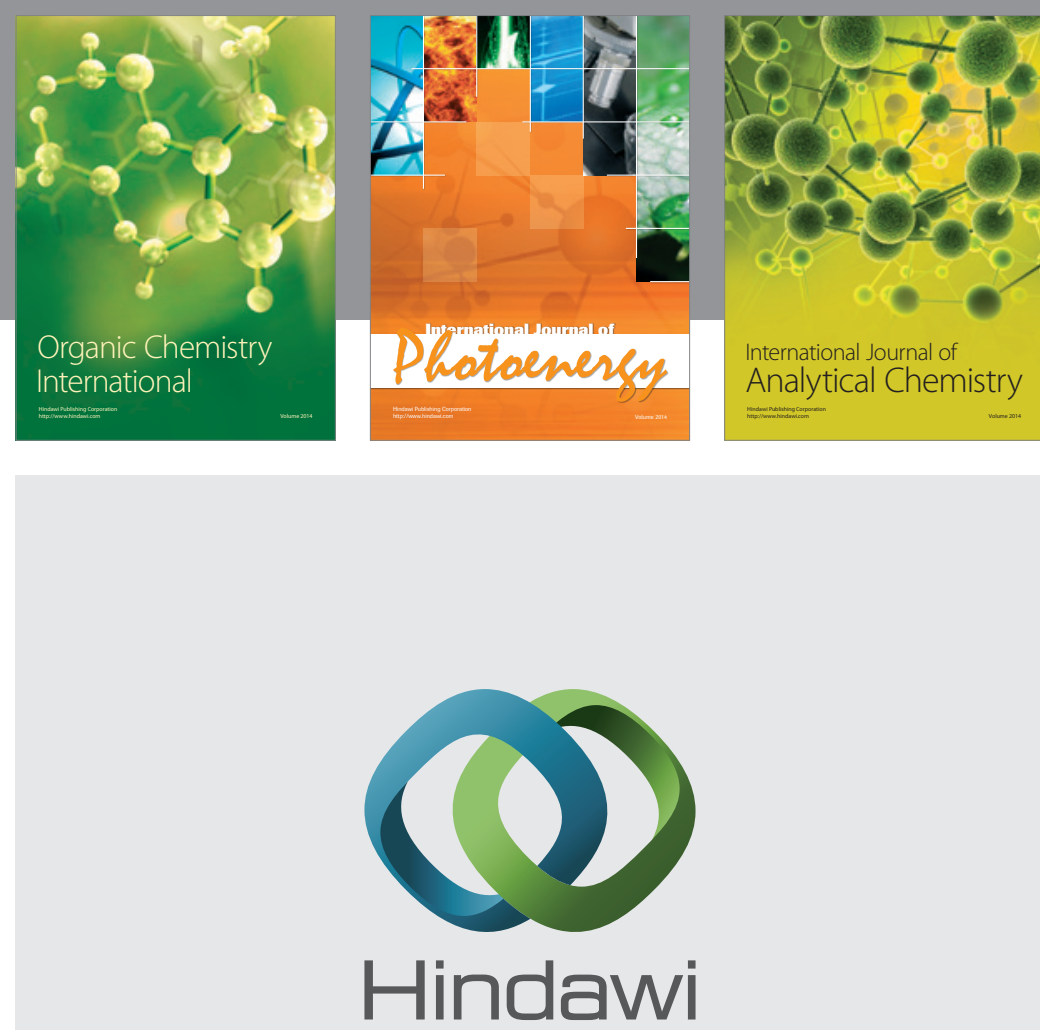

Submit your manuscripts at

http://www.hindawi.com
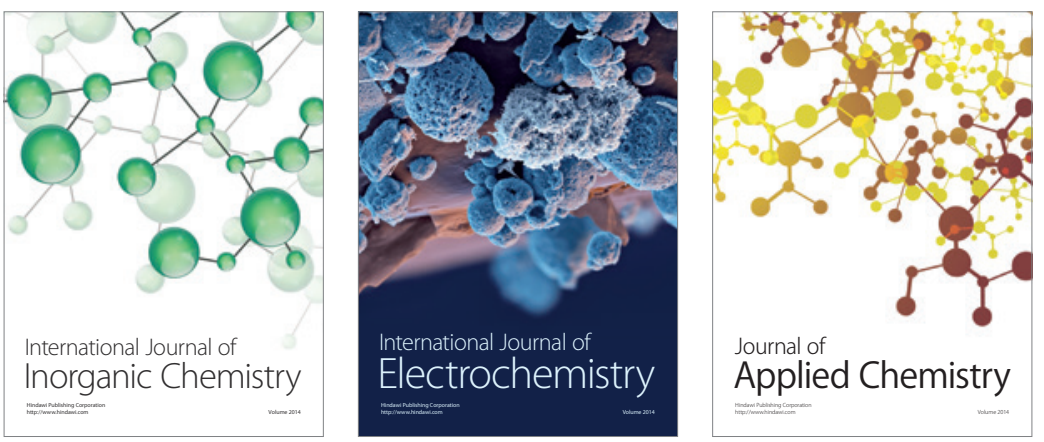

Journal of

Applied Chemistry
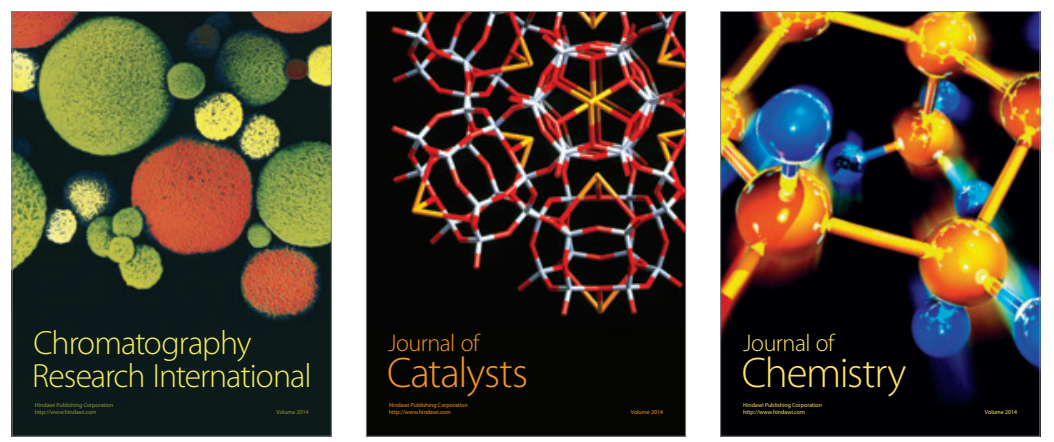
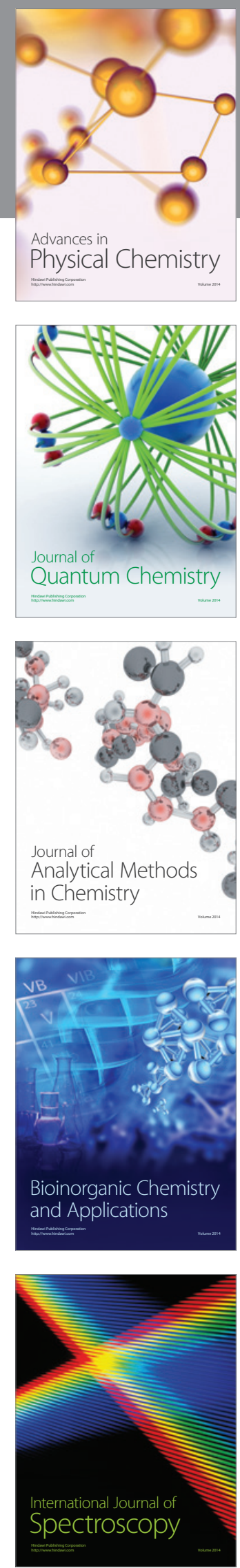